\title{
Evidence revealed the effects of rapid response system
}

Jae Hwa Cho

Division of Pulmonology, Department of Internal Medicine, Gangnam Severance Hospital, Yonsei University College of Medicine, Seoul, Korea

The first rapid response team (RRT) in Korea was formed in March 2008 at Asan Medical Center, although it was referred to as a medical alert team at that time. In the next decade, more than 10 other RRTs have been founded [1]. Several members of RRTs formed a committee and held academic meetings, and favorable results were published regarding the impact of RRTs on cardiac arrest [1].

The Korean government decided to implement a pilot project for a rapid response system to promote patient safety starting in 2019 [2]. In May 2019, a total of 15 RRTs were selected and received modest support from health insurance reimbursements.

Lee et al. [3] published a study entitled "Effect of a rapid response system on code rates and in-hospital mortality in medical wards". This before-and-after study showed significantly decreased code rates for operating time, but not for non-operating time. In-hospital mortality also decreased significantly. The RRTs did not consistently reduce mortality; however, a marked reduction of mortality was reported in that study. It is worth considering that there were more than 60 RRT activations per 1,000 admissions, and the RRT activation rate is generally related to the code rates.

In the near future, there will be big data about RRTs as a result of the government's pilot project. In Korea, it is expected that reports will analyze the effects of the rapid response system on the national scale.

Screening systems, such as the national early warning score and the modified early warning score, are currently used. In recent years, artificial intelligence-based programs dealing with the health care system have been created [4]. New screening programs are expected to be introduced and verified soon.

\section{CONFLICT OF INTEREST}

Jae Hwa Cho has been the editor-in-chief of Acute and Critical Care since 2016 and an editorial board member since 2008.

\section{ORCID}

Jae Hwa Cho

\section{Editorial}

Received: November 28, 2019

Accepted: November 28, 2019

Corresponding author Jae Hwa Cho

Division of Pulmonology, Department of Internal Medicine, Gangnam Severance Hospital, Yonsei University College of Medicine, 211 Eonju-ro, Gangnam-gu, Seoul 06273, Korea Tel: +82-2-2019-3317

Fax: +82-2-3463-3883

E-mail:jhcho66@yuhs.ac

Copyright () 2019 The Korean Society of Critical Care Medicine

This is an Open Access article distributed under the terms of Creative Attributions Non-Commercial License (http:// creativecommons.org/li-censes/by-nc/4.0/) which permits unrestricted noncommercial use, distribution, and reproduction in any medium, provided the original work is properly cited. 


\section{REFERENCES}

1. Lee BY, Hong SB. Rapid response systems in Korea. Acute Crit Care 2019;34:108-16.

2. Ministry of Health and Welfare. Rapid response system pilot project [Internet]. Sejong: Ministry of Health and Welfare; 2019 [cited 2019 Nov 27]. Available from: http://www.mohw.
go.kr/react/al/sal0101vw.jsp?PAR_MENU_ID=04\&MENU_ $\mathrm{ID}=040101 \&$ CONT_SEQ=348050\&page $=1$.

3. Lee HY, Lee J, Lee SM, Kim S, Yang E, Lee HJ, et al. Effect of a rapid response system on code rates and in-hospital mortality in medical wards. Acute Crit Care 2019;34:246-54.

4. Cho J. Artificial intelligence is around us. Let's pick up! Acute Crit Care 2018;33:185-6. 